\title{
Epidemiology of Adrenal Insufficiency Among Elderly Patients in a Convalescent Care Unit and One Year Outcome
}

\author{
(1) Doris Ka Ying Miu1, (1) Shiu Pui Man², (1) Stanley Kui Fu Tam³ \\ ${ }^{1}$ Wong Tai Sin Hospital, Department of Rehabilitation and Extended Care, Hong Kong \\ 2 Our Lady of Maryknoll Hospital, Department of Medicine and Geriatrics, Hong Kong \\ ${ }^{3}$ Hong Kong Buddhist Hospital, Department of Medicine, Hong Kong
}

\section{Abstract}

Objective: Adrenal insufficiency (Al) is associated with significant morbidity and mortality. The diagnosis of Al in elderly people is difficult with its non-specific presentation. The aim of this study is to describe the epidemiology, pattern of comorbidity and one-year outcome among elderly people after their initial diagnosis of Al.

Materials and Methods: Patients aged >65 years, who underwent the Short Synacthen test (SST) done during the period of 1.1.2014 to 30.6.2019, were retrieved. Basic demographic information, comorbidities as measured by the Charlson Comorbidity index (CCI), cause for admission, length of stay, one year unplanned readmission and death were recorded.

Results: Two hundred forty two patients with the mean age of 79.6 (standard deviation 8.75) were identified. The causes for admission were pneumonia (22.3\%), electrolytes abnormalities (11.6\%) urinary tract infection (UTI) (8.6\%) and poor oral feeding (7.8\%). Ninety four (38.3\%) were diagnosed to have Al. The most common indication for SST was electrolytes abnormalities. Unplanned readmission was present in 52.7\% of patients. Inpatient mortality was $11.6 \%$ and one year mortality was $44.8 \%$. There was no statistically significant difference between the Al and normal response group in age, gender, $\mathrm{CCl}$ score, length of stay, cause for admission, indication for SST and mortality. However, the Al group had a much lower baseline cortisol level (389 nmol/L vs. $192.4 \mathrm{nmol} / \mathrm{L}, \mathrm{p}<0.001)$.

Conclusion: This unrecognized group of elderly Al patients presents non-specifically. Respiratory and UTIs were the most common cause of admission. Physicians should be more alert on this easily unrecognized problem in the elderly. What is known on the subject and what does the study add: The incidence of $\mathrm{Al}$ in elderly subjects is on the rising trend, yet, it is easily unrecognized; this study highlights the importance of infection that contributes to $\mathrm{Al}$ development and the non-specific presentation of this disease in older population.

Keywords: Adrenal insufficiency, elderly, epidemiology

\section{Introduction}

Adrenal insufficiency (AI) is an uncommon problem, but it can be associated with significant morbidity and mortality (1). Causes of Al can be primary or secondary. Primary Al is due to inadequate production of adrenocorticosteroids as a result of damage to the adrenal gland. Common etiologies include autoimmune disease, infection, tumour or hemorrhage. Secondary $\mathrm{Al}$ is far more common than primary $\mathrm{Al}(2,3)$. It is due to disease in the pituitary or hypothalamus, causing inadequate adrenocorticotropic hormone production, which in turn reduces stimulation to adrenal cortex on corticosteroid production. Surveys in the Western population revealed that the prevalence of primary and secondary $\mathrm{Al}$ increased with time. The reported prevalence rate of primary and secondary $\mathrm{Al}$ in the 1990s was $9-14 / 10^{5}$ and $15-28 / 10^{5}$ population respectively $(2,4)$ which was much higher than those reported in the 1960s. However, a Japanese study has observed that the incidences of primary

Address for Correspondence: Miu Ka Ying Doris, Wong Tai Sin Hospital, Department of Rehabilitation and Extended Care, Hong Kong Phone: +852-35173668 E-mail: miuky@ha.org.hk ORCID: orcid.org/0000-0003-2923-4882

Received: 8 Jun, 2020 Accepted: 27 Jul, 2020

Cite this article as: Miu DKY, Man SP, Tam SKF. Epidemiology of Adrenal Insufficiency Among Elderly Patients in a Convalescent Care Unit and One Year Outcome. Eur J Geriatr Gerontol 2020;2(3):65-70

${ }^{\circ}$ Copyright 2020 by the Academic Geriatrics Society / European Journal of Geriatrics and Gerontology published by Galenos Publishing House. 
Al decreased with time (5). On the contrary, a nationwide Taiwanese study showed that the annual incidence of Al had continuously increased and elderly patients were accounted for the majority of this increase (6).

The diagnosis of $\mathrm{Al}$ is non-specific. It usually presented with variable symptoms such as fatigue, fever, poor appetite or gastrointestinal discomfort. It can progress to adrenal crisis with electrolytes disturbances, change of conscious level, shock and even death. Making the diagnosis of $\mathrm{Al}$ in older people is even more difficult. Older people have multiple comorbidities, and the symptoms might be mistaken as ageing processes (7). Epidemiological studies about Al among the elderly population are limited. Contributing factors and the signs and symptoms of $\mathrm{Al}$ are not well studied. Prevention of an adrenal crisis requires early recognition and prompt initiation of treatment. However, not much data are available on the incidence and prevalence of $\mathrm{Al}$, and the low awareness among medical professionals may lead to adverse outcome in an unrecognized adrenal crisis.

This study aims to describe the demographic profile, the pattern of comorbidity, contributing factors for older adults with $\mathrm{Al}$ and the 1-year outcome after the diagnosis of Al.

\section{Materials and Methods}

Hospital records were retrieved from 3 extended care units of a hospital network in Hong Kong. Case notes of subjects with age $>65$ and with Short Synacthen test (SST) done during the period 1.1.2014 to 30.6.2019 were retrieved. Those who were admitted as day-procedure for SST were excluded. Patient's age, gender, place of residence, comorbidities measured by Charlson Comorbidity index (CCI) (8) on admission, principal diagnosis and length of stay were recorded. An infection was classified as principal diagnosis or secondary diagnosis based on the condition that the disease was caused by an organism such as urinary tract infection (UTI), pneumonia or lower respiratory tract infection (LRTI) or where an infectious agent was coded (9). A virus was identified as present when specific viral agent was identified or where a diagnostic code had a viral agent included (9). Gastroenteritis was recorded by any code that specifies gastroenteritis whether it can be viral, bacterial or non-infectious in origin. Pneumonia/LRTI/chest infection was classified as pneumonia. Acute bronchitis and chronic obstructive pulmonary disease (COPD) with mentioning of infection were also considered as chest infection. In contrast, COPD, asthmatic exacerbation or bronchiectasis where the infection was not mentioned were not considered as infection.

Baseline cortisol level were recorded. Al is diagnosed by SST. For standard dose SST using 250 mcg tetracosactin, a failure of the cortisol level taken at $30 \mathrm{~min}$ to rise $>550 \mathrm{nmol} / \mathrm{L}$ from baseline is considered as positive (10). For low dose SST using one mcg of tetracosactin, a failure of $30 \mathrm{~min}$ cortisol to rise $>400 \mathrm{nmol} / \mathrm{L}$ from baseline is considered as positive (11). Indication for SST were be recorded. These include hypotension, electrolytes abnormality, unexplained poor general status, poor appetite, weight loss and other indications were collected. All subjects will be further followed for one year after their diagnosis. The proportion of patients with unplanned hospital readmission will be calculated. The discharge diagnosis and death were analyzed.

Subjects who failed the SST were considered as cases while those showed a normal response were considered as the control group.

\section{Statistics}

Descriptive statistics on baseline demographic variables as mean +/- standard deviation (SD) or median where appropriate. Between-groups comparison on demographic variables, possible precipitating causes, length of stay and inpatient mortality will be analyzed by t-test or Mann-Whitney $U$ test for continuous data and $x^{2}$ test for categorical data. Hospital readmission rate and mortality at one year were also compared. A p-value of $<0.05$ is considered as statistically significant.

This study is approved by the Hong Kong Hospital Authority Cluster Hospital Research Ethics Committee.

\section{Results}

There were a total of 292 SST done during the period of 1.1.2014 to 30.6.2019. Among them, 242 subjects met the inclusion criteria, and their records were retrieved. Figure 1 shows the consort flow diagram. The mean age was 79.6 (SD 8.75). There were 135 male subjects (55.6\%). One hundred seventy one low dose SST and 72 standard dose SST were performed. The most common cause for hospitalization was pneumonia (54, $22.3 \%$ ) followed by electrolytes abnormalities (28, 11.6\%), UTI $(21,8.6 \%)$ and poor oral feeding $(19,7.8 \%)$. There were 28 subjects died during the index admission. The in-patient mortality rate on the index admission was $11.6 \%$. During the one-year observation period after discharge from the index hospital admission, 152 subjects were readmitted with a median number of readmission of 2,96 of them were dead in one year and the one year mortality rate was 44.8\%. Indications for SST was shown in Figure 2. One hundred fourty eight (61.15\%) of them have a normal response to SST while 94 were diagnosed as $\mathrm{Al}$ (38.84\%). There was no statistically significant difference between the two groups on age, $\mathrm{CCl}$, causes for hospitalization and indications for SST. For electrolytes abnormalities, all of them were due to hyponatremia. There was also no statistical significant difference in hospital length of stay, inpatient and one year mortality between those who have normal and failed response to SST. However, the adrenal insufficient group has a much lower baseline cortisol level than the normal response 


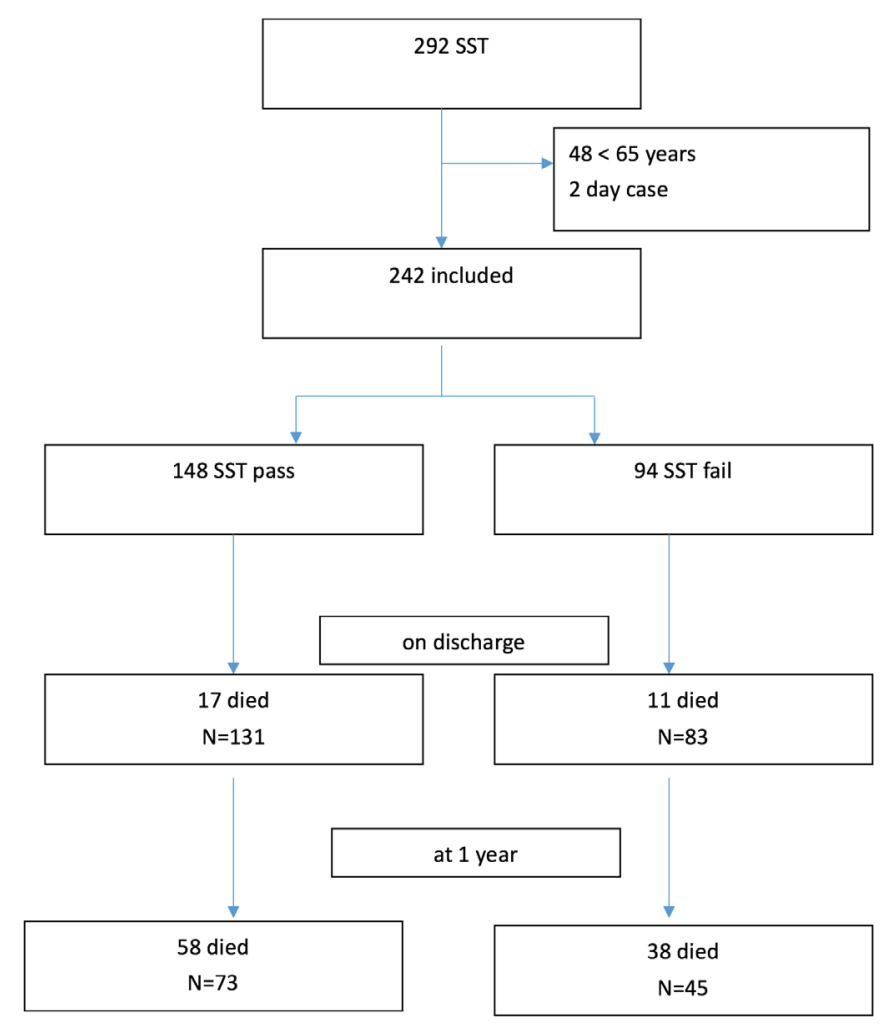

Figure 1. Consort flow diagram

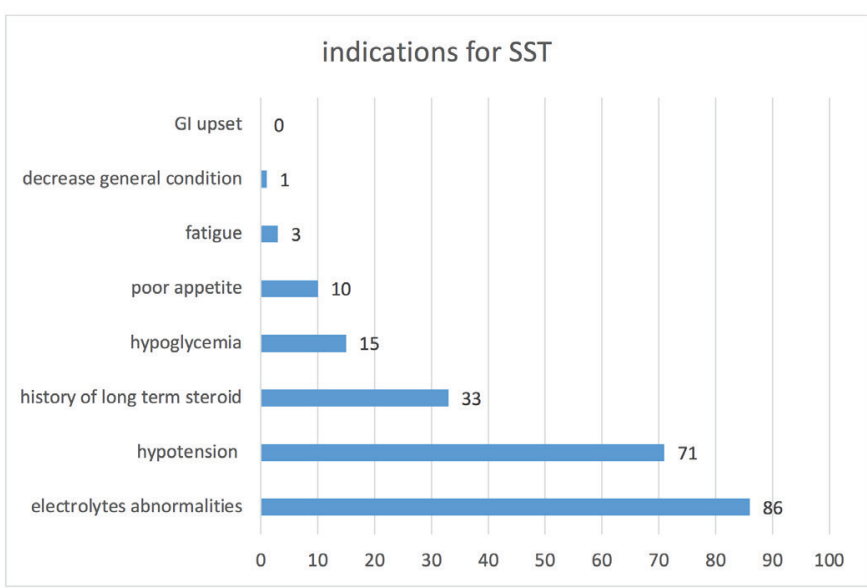

Figure 2. Indications for SST among the whole sample group each bar represents number of case

SST: Short Synacthen test, GI: Gastrointestinal

group (Table 1).

\section{Discussion}

There were many causes for Al. Many studies have reported on primary and secondary causes of $\mathrm{Al}$, mostly related to brain tumour. Primary $\mathrm{Al}$ is rare with an estimated incidence of $0.56-0.62 / 10^{5}(4)$, while for secondary $\mathrm{Al}$, no definite data on the incidence rate is available (12). A study in Taiwan (6) reported an increasing incidence of all-cause Al over a 13-year period of 6.4 to $15.2 / 10^{5}$. This can be attributed by an ageing population, increasing incidence of underlying diseases that lead to Al and perhaps, better diagnostic ability. The peak age for primary $\mathrm{Al}$ is reported to be around 40s while for secondary $A \mathrm{I}$, it was at the $6^{\text {th }}$ decade of life (2). In our study, the mean age for all causes of $\mathrm{Al}$ is around 80 , which is much older than those reported previously (2). In spite of this, it seems that Al in Asian/Chinese ethnicity is more common among the older age group. The proportion of subjects with Al with age $>80$ is on the rising trend as reported in a nationwide survey (6). The incidence rate was $10.6 \%$ in 1997, rising to more than twofold to $27 \%$ in 2008 . In echo with this, it is suggested that the growing number of $\mathrm{Al}$ in the elderly population may be due to an increase in the incidence of disease that precipitates adrenal failure. Moreover, older people have a lower sensitivity of the hypothalamus-pituitary-adrenal axis (HPA) to cortisol feedback (13) which might explain the higher incidence of Al among them. For secondary Al, sudden discontinuation of exogenous glucocorticoid therapy or hypothalamic-pituitary-adrenal axis suppression due to long term steroid use and inadequate cortisol production in response to physiological stress is common among elderly patients with long term steroid use due to COPD or arthritic conditions (14).

This study reveals the non-specific presentation of Al. Most cases of Al were diagnosed in an acute hospital setting in which the classical signs and symptoms of Al such as hypotension, hypoglycemia, hyponatremia will be presented to an acute hospital for urgent medical treatment. Those cases that managed in extended care and rehabilitation units were usually more stable with limited symptoms that seldom arouse awareness on the possibility of adrenal problem. In spite of this, we were still able to detect a certain proportion of patients who were undiagnosed. We postulated that this underdiagnoses of Al might be due to lack of unawareness or the non-specific presentation of $\mathrm{Al}$ in older adults.

Our findings showed that pneumonia was the most common cause for acute hospital admission in subjects with newly diagnosed Al. Bacterial infection will impact subjects with Al. Studies have shown that patients with hypoadrenalism have a higher risk of bacterial infection $(15,16)$. Furthermore, the presence of a bacterial infection will provoke a strong inflammatory cytokine response that stimulates the HPA to increase cortisol production. This can lead to a reduction in inflammation and protect against tissue damage. However, in the case of hypoadrenalism, the lack of an increase in cortisol production will lead to a severe inflammatory response which may result in tissue damage and systemic effects including hypotension, shock and organ failure (17). A study in Japan (18) showed that infectious disease was the major cause for inducing adrenal crisis. Another study (19) supported the finding of a close relationship between the severity of communityacquired pneumonia, inpatient mortality and the average 


\begin{tabular}{|c|c|c|c|}
\hline & SST pass $(N=148)$ & SST fail $(N=94)$ & p \\
\hline Age (years) & 79.43 (SD 9.17) & 79.61 (SD 8.75) & 0.706 \\
\hline Gender (male) & $82(57.77 \%)$ & $52(55.32 \%)$ & 1 \\
\hline Old age home residents & $36(24.32 \%)$ & $25(26.6 \%)$ & 0.762 \\
\hline In patient mortality & $17(11.4 \%)$ & $11(11.7 \%)$ & 1 \\
\hline One year mortality & $58(44.2 \%)$ & $38(45.7 \%)$ & 0.892 \\
\hline Baseline cortisol level (nmol/L) & 389.89 (SD 143.56) & 192.41 (SD 130.67) & $<0.001(95 \% \mathrm{Cl}-233.15,161.81)$ \\
\hline $\begin{array}{l}\text { Indications for SST } \\
\text { Hypotension } \\
\text { Electrolytes abnormalities } \\
\text { Fatigue } \\
\text { Poor appetite } \\
\text { Hypoglycemia } \\
\text { History of long term steroid } \\
\text { Decrease general condition }\end{array}$ & $\begin{array}{l}49(33.1 \%) \\
56(37.83 \%) \\
1(0.6 \%) \\
6(4.1 \%) \\
7(4.7 \%) \\
15(10.1 \%) \\
8(5.4 \%)\end{array}$ & $\begin{array}{l}21(22.3 \%) \\
30(31.9 \%) \\
2(2.1 \%) \\
9(9.6 \%) \\
8(8.5 \%) \\
18(19.1 \%) \\
8(8.5 \%)\end{array}$ & $\begin{array}{l}0.082 \\
0.409 \\
0.335 \\
0.591 \\
0.278 \\
0.055 \\
0.428\end{array}$ \\
\hline
\end{tabular}

length of hospitalization with adrenal function. A recent study reported that infection was the most prevalent comorbidity for adrenal crisis among adrenal insufficient subjects, followed by respiratory disease (20). There are many risk factors for adrenal crisis among subjects with chronic Al. It is well reported that initial illness, especially sepsis, was associated with Al (21). From our study, there were a number of patients who were newly diagnosed as having Al only after they were transferred to convalescence unit. This reiterated the fact that presentation of $\mathrm{Al}$ is very vague and easily missed. This group of patients may have more comorbidities and may be much older in age. The altered HPA function in older people would have an influence on the onset of adrenal crisis (22). Therefore, adrenal failure thus developed would lead to a more severe condition than the younger population and higher incidence as well. A population survey found that excluding those with chronic Al, patients with the adrenal crisis were older and had more comorbidities than those with primary and central Al (23). Thus, physicians caring for patients with $\mathrm{Al}$, besides attention on the general status and predisposing conditions, the patient's age and comorbidities should also be taken into account.

The most common indication for performing SST in our sample population was electrolytes abnormalities. This is one of the alerting sign for the diagnosis of $\mathrm{Al}$ (24). Al is not a common cause for hyponatremia (25). However, it has been described that a low serum sodium level is present in $80 \%$ of cases with adrenal crisis (26). In contrast, a more recent study (6) showed that among $4.85 \%$ of patients with newly diagnosed Al has electrolytes imbalance. The author postulated that the severity of $\mathrm{Al}$ in their population group does not reach the level of adrenal crisis. This is in accordance with the setting of nonacute convalescence unit diagnosing Al. Those patients with a borderline adrenal reserve will have subtle signs and symptoms that would have been detected in convalescence in which the longer length of hospital stay would enable clinicians to have a thorough investigation of non-specific presentations. Thus a high index of suspicion should help to alert clinicians on the diagnosis of Al.

The second most common indication for performing SST is unexplained hypotension. Those with very low blood pressure or even shock would have been detected during an adrenal crisis. Those frail elderly patients with relatively low blood pressure, but asymptomatic, would have been missed. Clinicians managing patients with asymptomatic hypotension may consider this low blood pressure was due to dehydration, occult sepsis or side effects of drugs. These diagnostic uncertainties may differ between clinicians with varying level of experience. Both hypotension and electrolytes imbalance was only present in 22-31\% of our subjects. This low prevalence of the classical signs and symptoms of $\mathrm{Al}$ warrant thorough evaluation of elderly patients with non-specific signs and symptoms. Patients with chronic Al may present non-specifically and only when exposed to medical conditions such as infection will result in adrenal crisis and mortality.

Inpatient and one year mortality were high in our study population. $11.6 \%$ of our sample died during the index hospitalization while the one year mortality was up to $40 \%$. This reflects the severity of medical problems and the poor health status of our study sample. However, our study showed 
that the one year mortality rate were similar between subjects with or without Al. This could represent the effectiveness of the replacement therapy. As such, offering more screening in suspected patients may benefit more patients with undiagnosed Al.

Furthermore, it is postulated that those underdiagnosed hypoadrenal patients would have their medical illness treated in acute hospital and discharge back home directly. There is a possibility that they will develop adrenal crisis after another episode of medical illness. They are a group of vulnerable patients with potentially lethal outcome. It is suggested that those frail elderly with a low or borderline electrolytes abnormalities and/ or unexplained low blood pressure should have screening for Al.

Management of $\mathrm{Al}$ is practically difficult in older patients. The pharmacokinetics and pharmacodynamics of drugs change with age. Polypharmacy, which is common in the elderly population, complicate drug-drug interaction. Cognitively impaired elderly patients will have compliance issues (27), and the increasing prevalence of comorbid conditions with ageing will further influence the disease management. Typical signs and symptoms of infection such as fever may not be experienced by elderly patients. Thus, the stress dose of glucocorticoid may not be administered. Furthermore, delirium is common among elderly with sepsis, self-management of taking extra steroid dose will not be possible.

There were several limitations in our study. Only database on SST was retrieved. We cannot identify the true incidence of Al among subjects in the convalescence care unit. We could not differentiate primary from secondary $\mathrm{Al}_{\text {, although the }}$ management for both causes of Al remains the same. The severity of Al cannot be adequately assessed. We only have data on the baseline cortisol and electrolytes level. There was no information on the clinical state of the subjects nor the blood pressure response. Details on drug prescription were not recorded. The cause for hospital readmission were not known. The incidence of Al may be under-estimated since those cases that were diagnosed and treated in ambulatory setting were not included. There was no information on the infectious agent causing the sepsis.

Finally, we cannot ascertain the cause and effect on the relationship between $\mathrm{Al}$ and as it was only a retrospective study.

\section{Conclusion}

A certain proportion of elderly people with Al were unrecognized in acute hospital and present non-specifically. Infection of the chest and urinary tract were the most common comorbidity. Hypotension was the most common manifestation of $\mathrm{Al}$ among convalescence care elderly patients. Clinicians should be more aware of the signs and symptoms of $\mathrm{Al}$, which is easily overlooked in the elderly population.

\section{Ethics}

Ethics Committee Approval: This study is approved by the Hong Kong Hospital Authority Cluster Hospital Research Ethics Committee (date: 18.12.2019, number: KC/KE- 19-0218/ER-2).

Informed Consent: Since this is a retrospective study, no patient consent is required.

Peer-review: Internally peer-reviewed.

\section{Authorship Contributions}

Concept: D.K.Y.M., Design: D.K.Y.M., Data Collection or Processing: D.K.Y.M., S.P.M., S.K.F.T., Analysis or Interpretation: D.K.Y.M., Literature Search: D.K.Y.M., Writing: D.K.Y.M., S.P.M., S.K.F.T.

Conflict of Interest: No conflict of interest was declared by the authors.

Financial Disclosure: The authors declared that this study received no financial support.

\section{References}

1. Bergthorsdottir $R$, Leonsson-Zuchrisson $M$, Oden $A$, Johannsson $G$. Premature mortality in patients with Addision's disease: a population-based study. J Clin Endocrinol Metab 2006;91:4849-4853.

2. Arlt W, Allolio B. Adrenal insufficiency. Lancet 2003;361:1881-1893.

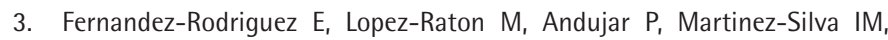
Cadarso-Suaraez C, Casanueva FF, Bernabeu I. Epidemiology, mortality rate in a homogenous population of hypopituitary patients. Clin Endocrinol 2013;78:278-284.

4. Lovas K, Husebye ES. High prevalence and increasing incidence of Addison's disease in Western Norway. Clin Endocrinol (Oxf) 2005;56:787-791.

5. Nomura K, Demura H, Sacuta T. Addison's disease in Japan: characteristics and changes revealed in a nationwide survey. Intern Med 1994;33:602-606.

6. Chen YC, Lin YH, Chen SH, Chen YC, Chou LF, Chen TJ, Hwang SJ. Epidemiology of adrenal insufficiency: A nationwide study of hospitalizations in Taiwan from 1996-2008. J Chin Med Assoc 2013;76:140-145.

7. Tayal SC, Bansal SK, Chadha DK. Hypopituitarism: a difficult diagnosis in elderly people but worth a research. Age Ageing 1994;23:320-322.

8. Charlson ME, Pompei P, Ales KL, MacKenzie CR. A new method of classifying prognostic comorbidity in longitudinal studies: development and validation. J Chronic Dis 1987;40:373-383.

9. Rushworth RL, Torpy DJ. A descriptive study of adrenal crises in adults with adrenal insufficiency: increased risk with age and in those with bacterial infection. BMC endocr disorder 2014;14:79.

10. Dorin RI, Qualls CR, Crapo LM. Diagnosis of adrenal insufficiency. Ann Intern Med 2003;139:194-204.

11. Park YJ, Park KS, Kim JH, Shin CS, Kim SY, Lee HK. Reproducibility of the cortisol response to stimulation with the low dose (1 microg) of ACTH. Clin Endocrinol (Oxf) 1999;51:153-158.

12. Arlt W, Allolio B. Adrenal insufficiency. Lancet 2003;361:1881-1893.

13. Beale $E$, Zhu J, Belzberg $H$. Changes in serum cortisol with age in critically ill patients. Gerontology 2002;48:84-92.

14. Scheutz $P$, Christ-Crain $M$, Schild $U$, Suess $E$, Facompre $M$, Baty $F$, Nusbaumer C, Brutsche M, Müller B. Effects of a 14-day course of systemic corticosteroids on the hypothalamic-pituitary-adrenal axis in patients with 
acute exacerbation of chronic obstructive pulmonary disease. BMC Pul Med 2008;8:1.

15. Smans LC, Souverein PC, Leufkens H, Hoepelman Al, Zelissen PM. Increased use of anti-microbial agents and hospital admission for infections in patients with primary adrenal insufficiency: a cohort study. Eur J Endocrinol 2013;168:609-614.

16. Chen YC, Chen YC, Chou LF, Chen TJ, Hwang SJ. Adrenal insufficiency in the elderly: a nationwide study of hospitalization in Taiwan. Tohoku J Exp Med 2010:221:281-285.

17. Wotton CJ, Goldacre MJ. Risk of invasive pneumococcal disease in people admitted to hospital with selected immune-mediated diseases: record linkage cohort analysis. J Epidemiol Community Health 2012;66:1177-1181.

18. Takayanagi R, Miura K, Nakagawa $H$, Nawata H. Epidemiologic study of adrenal gland disorders in Japan. Biomed Pharmacother 2000;54(Suppl 1):164s-168s.

19. Gotoh S, Nishimura N, Takanashi O, Shiratsuka H, Horinouchi H, Ono H, Uchiyama N, Chohnabayashi N. Adrenal function in patients with community-acquired pneumonia. Eur Respir J 2008;31:1268-1273.

20. Ono $Y$, Ono $S$, Yasunaga $H$, Matsui $H$, Fushimi $K$, Tanaka $Y$. Clinical features and practice patterns of treatment for adrenal crisis: a nationwide crosssectional study in Japan. Eur J Endocrinol 2017;176:329-337.
21. Ben-Shlomo A, Mirocha J, Gwin SM, Khine AK, Liu NA, Sheinin RC, Melmed S. Clinical factors associated with biochemical adrenal-corticoid insufficiency in hospitalized patients. Am J Med 2014;127:754-762.

22. Gaffey $A E$, Bergeman CS, Clark LA, Wirth MM. Ageing and the HPA axis: stress and resilience in older adults. Neurosci Biobehav Rev 2016;68:928945.

23. Iwasaku M, Shinzawa M, Tanaka S, Kimachi K, Kawakami K. Clinical characteristics of adrenal crisis in adult population with and without predisposing chronic adrenal insufficiency: a retrospective cohort study. BMC Endocr Disord 2017;17:58.

24. Jacobi J, Schnellhardt S, Kulschewski A, Amann KU, Kuefner MA, Eckardt $\mathrm{KU}$, Hilgers KF. An unusual cause of hyponatremia. Nephol Dial Transplant 2010;25:998-1001.

25. Winchester Behr T, Somnenblick M, Nesher G, Munter G. Hyponatremia in older people as a sign of adrenal insufficiency: a case control study. Intern Med J 2012;42:306-310.

26. Arlt $W$. The approach to those adult with newly diagnosed adrenal insufficiency. J Clin Endocrinol Metab 2009;94:1059-1067.

27. Wynne HA, Blagburn J. Drug treatment in ageing population: practical implication. Maurtias 2010;66:246-250. 